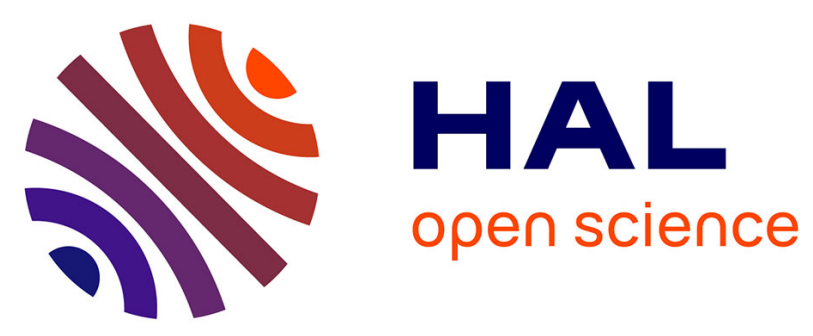

\title{
Emotional experiences one year after a traffic accident: An exploratory study of verbatim accounts of the ESPARR cohort
}

\author{
Barthélémy-Claude Tavernier, Laurence Paire-Ficout, Pierrette Charnay, \\ Hélène Tardy, Marie Izaute, Laetitia Silvert, Martine Hours
}

\section{To cite this version:}

Barthélémy-Claude Tavernier, Laurence Paire-Ficout, Pierrette Charnay, Hélène Tardy, Marie Izaute, et al.. Emotional experiences one year after a traffic accident: An exploratory study of verbatim accounts of the ESPARR cohort. Injury, 2017, 48 (3), pp. 659-670. 10.1016/j.injury.2017.01.011 . hal-01491439v2

\author{
HAL Id: hal-01491439 \\ https://hal.science/hal-01491439v2
}

Submitted on 26 Apr 2017

HAL is a multi-disciplinary open access archive for the deposit and dissemination of scientific research documents, whether they are published or not. The documents may come from teaching and research institutions in France or abroad, or from public or private research centers.
L'archive ouverte pluridisciplinaire HAL, est destinée au dépôt et à la diffusion de documents scientifiques de niveau recherche, publiés ou non, émanant des établissements d'enseignement et de recherche français ou étrangers, des laboratoires publics ou privés. 


\title{
Emotional experiences one year after a traffic accident:
}

\section{An exploratory study of verbatim accounts of the ESPARR cohort}

\begin{abstract}
The aim of this study was to characterize different possible profiles of emotional experiences of victims of traffic accident based on verbatim accounts collected one year after the accident, and to relate these profiles to various socio-demographic and health data. A hierarchical cluster analysis of the emotional lexicon was made by categorizing and quantifying the EMOTAIX® lexicon using Tropes@ text analysis software. Out of the 751 selected subjects, 328 expressed one or more emotional experiences. A link appeared between quality of life (QoL), posttraumatic stress disorder (PTSD) and the valence of expressed emotions. Injury severity and history distinguished two sets expressing negative-valence emotional experience. Paradoxically, a group also emerged with a large proportion of severely injured persons, associated with the expression of positive-valence emotional experiences and with domains of QoL and PTSD ${ }^{1}$. The analysis of subjective data sheds light on the experience of traffic accident victims and shows a way forward for research and clinical intervention.
\end{abstract}

Keywords: Emotional experience, Narrative, PTSD, Quality of life, Victims of traffic accidents.

\footnotetext{
${ }^{1}$ QoL: quality of life

PTSD: post-traumatic stress disorder
} 


\section{Introduction}

Projecting data from the Registry of Road Accidents in the Rhône administrative area of France (Registre des Accidents de la Route dans le Rhône) between 1996 and 2004, the annual average of road injuries in France can be estimated to exceed 500,000, of which more than 60,000 are considered severe (Amoros et al., 2008). Significant links have been established between injury severity and time needed for complete recovery (Hours et al., 2013), time to return to work (Fort et al., 2011), severity of pain (Fort et al., 2011; Hours et al., 2010), impact on families (Hours et al., 2013), further deterioration of quality of life (QoL) (Christensen et al., 2011; Khati \& al, 2013; Sampalis et al., 2006), and post-traumatic stress disorder (PTSD) (Chossegros et al., 2011; Davydow et al., 2009).

PTSD is common to all traffic accident victims (Blanchard et al., 1995; Ehlers et al., 1998; Holeva et al., 2001; Kearns et al., 2012; Murray et al., 2002; Nhac-Vu et al., 2014; Rabe et al., 2006) and encompasses a wide range of unstable emotional experiences. In the immediate aftermath of trauma almost all victims suffer re-experiencing (repetitive and intrusive memories of events, flashbacks, etc.), avoidance (of places, objects and thoughts connected to the traumatic event) and hyperarousal (difficulty in concentration, irritability, anger, etc.), as well as various cognitive and emotional effects (Brewin \& Holmes, 2003; Bryant, 2011; Jones et al., 2007). Fortunately, in the great majority of cases, these symptoms then resolve naturally (Bryant, 2011; Kearns et al., 2012).

Yet resolution of PTSD does not always signify the complete recovery of traffic accident victims. Investigation of the emotional experiences of these victims through verbatims can deepen our understanding of their functioning and thus better direct proposed provision of early care.

Analyzing subjective data is usually considered as methodologically tricky (Hendrick, 2002). However, analysis of responses to open questions is also particularly suited to data investigation, notably when it concerns emotional feelings. Indeed, the study of verbatim transcripts, in spite of their subjectivity, may be the best means of evaluating emotional experience (Feldman-Barrett, 2006; 2007; Lindquist \& Gendron, 2013).

Besides, emotion is hard to encompass at the conceptual level (Feldman-Barrett, 2006; Brillon et al., 1996; Dalgleish, 2004; Minsky, 1986, 2006). Still, nowadays leading authors in the field usually agree on operationally defining emotion as a construct of at least four components: the subjective feeling, physiological, behavioural and cognitive components (Feldman-Barrett, 2006; 2007; Bradley \& Lang, 1994; Dalgleish, 2004; Gil, 2009; Russell, 2009; Russell \& FeldmanBarrett, 1999; Scherer, 2005). Importantly for our research, these components are considered as dynamically and recursively interconnected: a change in one component will generate changes in the other components. For example, activation of the physiological component (arousal, which mostly relates to the activation of the autonomic nervous system and endocrine system) can lead to 
heart rate acceleration, increased blood pressure and cortisol release. This activation can translate at the behavioural level, for example into a state of alertness, a greater perceptual sensitivity, and faster cognitive processing and motor responses (Scherer, 2005). Similarly, the cognitive component (appraisal), which consists in an evaluation of the situation, can modify the experienced emotion, which will reactively change the mental state and thus the way of evaluating the situation.

Evidence for these retroactive loops is supported by contemporary neuroscience (Dalgleish, 2004). It is consistent with the concept of circular causality (Bertalanffy, 1968; Maturana \& Varela, 1994, Varela et al., 1991) that, with regard to emotional experience, refers to a dynamic process, constantly balancing the various components described above. Seen from this perspective, emotional experiences become more or less effective means of adaptation (Minsky, 2006), in order to compensate for environmental disturbance (for example, a traffic accident) in a recursive dynamic.

Following the enactive theory of Francisco J. Varela, Feldman-Barrett (2006) places action and perception at the centre of her 'conceptual act' model of emotion. Emotional experience is here the result of conceptualizing a basic form of affective response (the core affect concept that is close to arousal as described above) via an act of categorization. The latter is related to both emotional awareness acquired through prior experience and to the immediate circumstance. The result is an emotional experience primed for action. For example, the sight of a bear in a forest triggers an intense physiological activation, which is arousal (comparable to the core affect); the behavioural fight-or-flight response is triggered; the feeling of fear takes hold following categorization (see Gil, 2009, p.15) in an interdependent feedback loop.

Most previous work in this field has been concerned with emotional experiences in the immediate aftermath of trauma, or a few months following (Jones et al., 2007). To our knowledge, only one recent study was concerned with emotional verbatim of patients with physical injury (Wiseman et al. 2016). This is a follow-up qualitative study which explore 14 patients experience of emotional wellbeing at 3 and 6-mouths after injury. In the present study, verbatim accounts found among questionnaire responses of the ESPARR (Etude et Suivi d'une Population d'Accidentés de la Route dans le Rhône $)^{2}$ cohort of traffic victims from the Rhône administrative area provide an opportunity for this exploratory work. One open question posed at the one-year follow-up allows the victim to express his or her feeling: "In general, what are your feelings today about this accident that happened to you one year ago?"

The present study aimed at categorizing the lexicon of victims' emotional experiences one year after a traffic accident in order to group them together into distinct profiles. The goal was then to study the relationship of these profiles to lesion severity, QoL, PTSD and medical history of

\footnotetext{
${ }^{2}$ http://esparr.inrets.fr/ (visited November the 29th of 2016).
} 
ESPARR cohort members and, by characterizing them, to reveal possible signs of adaptation to the consequences of a traffic accident.

\section{Method}

\section{Participants}

The population study is based on the ESPARR cohort which was monitored between October 2004 and July 2006 and consisted of 1,168 victims of traffic accidents that were at least 16 years old at the time of their accident. This prospective cohort is intended to analyze the health, familial, social and occupational prospects of survivors of traffic accidents. It derives from the Rhône registry of road accidents that has since 1995 documented victims injured in a traffic accident in the Rhône administrative area of France. After an initial interview, the longitudinal follow-up comprises self-administered questionnaires at six months, then one, two, three and five years after the accident. The sample has previously been described in articles that focused on functional outcomes (Hours et al., 2010, 2013).

\section{Material}

This study is therefore based on the analysis of the verbatim of participants who responded to the question: "In general, what are your feelings today about this accident that happened to you one year ago?"

\section{Socio-demographic data and medical history}

Socio-demographic data (gender, age at the time of accident, educational level) were reported, as well as personal events that occurred in the year preceding the accident and the medical history of each patient.

\section{Injury data}

Injury data were collected from medical records and encoded by the Registry physician experienced in lesion coding. Their severity was assessed by means of the Abbreviated Injury Scale (AIS) (AAAM, 1990). M-AIS (Maximum-AIS, rated from 1: minor to 6: untreatable) is the highest AIS score, often dichotomized between not very severe diagnosis, corresponding to M-AIS $<3$, and M-AIS $\geq 3$ implying a severe diagnosis. Aside an overall score, M-AIS is assessed for each body region: head, face, neck, thorax, abdomen, spine, upper limbs, lower limbs, skin. 
The New Injury Severity Score (NISS) is specially developed for the assessment of multipletrauma patients. It corresponds to the sum of the squared AIS scores for the three most severe injuries.

\section{Quality of Life}

The World Health Organization Quality of Life - Bref scale (WHOQOL - Bref) assesses QoL by means of a self-administered questionnaire, comprising six dimensions: overall QoL; health satisfaction; and QoL self-assessments for physical health, psychological health, social relationships, and environmental health (WHOQOL group, 1995). Responses to each question are given on a 5-point Lickert scale and weighted by an algorithm to calculate profile scores (scale 0100 to be congruent with the generic WHOQOL questionnaire). Higher scores reveal a better quality of life.

\section{Post-traumatic stress disorder}

PTSD is measured according to the Post-Traumatic Stress Disorder Checklist Scale (PCLS), a self-administered questionnaire with 17 items (graded from 1: 'not at all' to 5: 'very often') that follow the 17 diagnosed symptoms of PTSD from the Diagnostic and Statistical Manual of Mental Disorders, Fourth Edition (DSM-IV). The three sub-components of PTSD are recorded: reexperiencing (criterion B) for items 1 to 5; avoidance (criterion C) for items 6 to 12; and persistent symptoms of increased arousal (criterion D) for items 13 to 17 . The traffic accident (criterion A) and the assessment one year after the event (criterion E) were associated to the evaluation. The threshold score of 44 indicates possible PTSD (Blanchard et al., 1996).

\section{Data analysis}

The analysis of verbatim transcripts provided textual data that were then statistically clustered. The resulting clusters were then compared to socio-demographic data and medical history, lesion data, QoL and PTSD to determine associations.

The profiles of emotional experiences were created through extraction, categorization and counting of the emotional lexicon found in verbatim responses to the question about feelings in the ESPARR questionnaire one year after the accident. The EMOTAIX ${ }^{\complement 3}$ emotional lexicon, under Tropes $^{\odot}$ (version 8.4$)^{4}$ software, was used to analyze the written production of the accident victims. This lexicon enables automatic identification, categorization and counting of the emotional lexicon

\footnotetext{
${ }^{3}$ http://centrepsycle-amu.fr/outils-recherche (visited November the 29th of 2016).

${ }^{4}$ http://www.tropes.fr/ (visited November the 29th of 2016).
} 
contained in oral or written scripts, of whatever length or word count (Piolat \& Bannour, 2009, p. $655)$.

The EMOTAIX $^{\odot}$ scenario (cf. link note 3) "is organized into three hierarchical levels of content category nesting" (Piolat \& Bannour, 2009, p. 684) to which classification by positive or negative valence is added. Categories are displayed in the form of a disk according to the principle of opposition across a central symmetry. Each category, whatever its hierarchical level, is found opposite a counterpart of inverse valence that allows one to take note of the negative form, and if necessary, to place the term in the opposite category. For example, the global level category (comprising six major themes) of anxiety is found opposite that of composure, while at the intermediate level (comprising eighteen median themes) tension is opposite to calm, and at the specific level (fifty-six precise themes) panic is opposite to serenity. Finally, emotional experiences referring to surprise, impassiveness and non-specific emotions are grouped in a primary level.

In addition, each of the fifty-six themes of the specific level, and the three themes of the primary level, are subdivided according to usage of the term (literal meaning - figurative meaning). This "manual" re-classification of different figurative terms is essential and allows the inclusion of a large number of words used in different expressions not always linked to the register of emotional experience ${ }^{5}$.

\section{Variables used for hierarchical clustering}

Textual analysis provided, for each analyzed extract, the number of words of each theme that referred to the emotional lexicon at the specific level (among fifty-six themes). It was then possible to sum the specific emotions to obtain a more general analysis in terms of feelings (intermediate level, eighteen themes) or one that was more global in terms of affects (six themes). The intermediate level was finally chosen because it allowed good discrimination of the participants. The hierarchical classification was thus carried out with the eighteen themes recounting feelings, to which were added the two valence variables taking into account the manually reclassified non-specific emotions.

\footnotetext{
5 The French word "cœur" (heart) is used in numerous expressions: "avoir le cœur qui s'emballe" (to have a racing heart) following a "coup de foudre" (lit. bolt of lightning, or fig. love at first sight) or with intense effort, to undergo "une opération à cour ouvert" (open-heart surgery) or "parler à cour ouvert" (to speak frankly), "avoir un coup de cœur" (to have a favorite, or a crush, or to really like) or "subir un coup au cour" (to experience love at first sight, or a sudden crush), "avoir le cœur sur la main” (to have one's heart in one's hand: i.e., to be open-handed or generous), "apprendre par cour" (to learn by heart), etc. The verification stage allows a term to be disallowed, placed, re-classed, or accorded a valence according to the context.
} 
The first step was to create distinct profiles of emotional experience and then to examine the characteristics of each one regarding the demographic and medical variables listed above.

Given our theoretical approach, an idiosyncratic approach focused on individuals, rather than a nomothetic approach focused on variables, seemed appropriate, to take account of the unique organization of variables (emotional lexicon categorization) within the different profiles (Hendrick, 2002). Hierarchical cluster analysis allowed emotional experiences to be differentiated by clustering similar profiles, with the distance between each pattern of variables in a " $n$ " variable space calculated as a coefficient of the Euclidian distance squared. Use of the 'Ward method' minimized intra-group variance. A dendrogram (similarity tree) thus obtained represents the different possible clusters according to cut-off level. Group quality was assessed on analysis of variance (ANOVA) on the variables underlying the formation of each group, with pairwise multiple comparison of group means, and Bonferroni correction to avoid increasing first-order risk. Membership of a group thus became in itself an explanatory factor.

A non-parametric Mann-Whitney U test was used to compare groups up to three and then nine groups, according to cut-off levels $\mathrm{B}$ and $\mathrm{C}$ on the similarity tree. Finally, further ANOVAs compared the data of each group to various variables: socio-demographic (age), injury severity on NISS, PTSD on PCLS, and QoL on WHOQOL-Bref. Chi-square tests were also performed on history and on bimodal variables: socio-demographic (gender), injury severity (threshold of 3 on MAIS), PTSD (threshold of 44 on PCLS). Description of the nine groups characteristics is based on these ANOVAs.

\section{Results}

\section{Descriptive sample}

Of the 1,168 participants of the ESPARR cohort, 886 answered to a questionnaire at one year (75.9\%) (Figure 1). The 282 non-respondents were more often young men with minor injuries. 


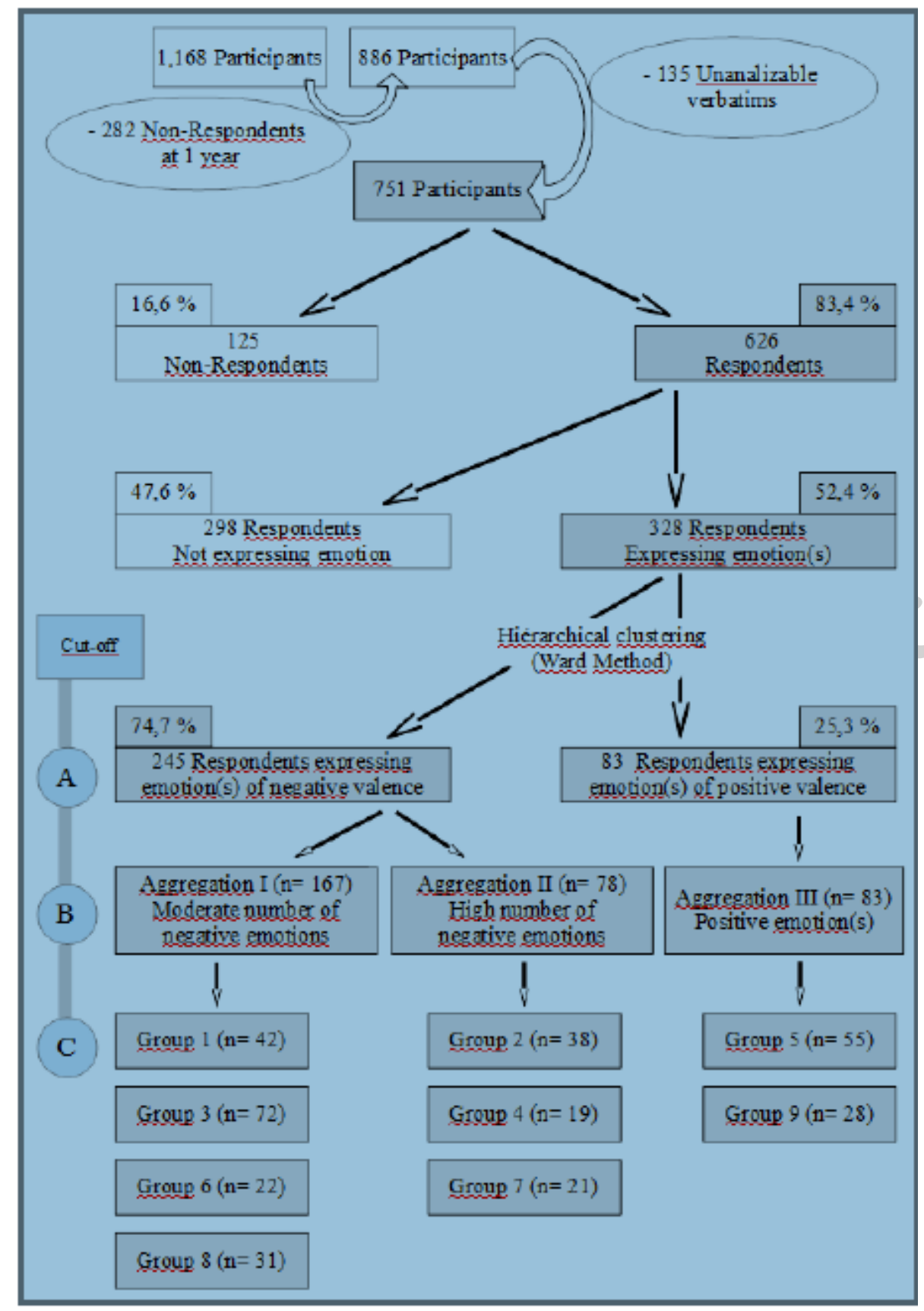

Figure 1: Flowchart describing the selection of the participants in the study, ESPARR cohort

Out of the 886 respondents, 135 were excluded from the analysis because the questionnaire administered to them did not include the 'feelings question', or transcribing their verbatim accounts was problematic. This study is therefore based on the analysis of $751(64 \%)$ participants.

Of these 751 participants, $626(83.4 \%)$ actually answered the question relating to feelings. Non-respondents to the question showed a significantly higher proportion of persons who suffered from serious injuries (M-AIS $\geq 3$ ), notably those with injuries to the lower and upper limbs, as well as a considerable proportion of persons with multiple trauma. Furthermore, the non-respondent group was significantly older, and comprised a greater proportion of persons who already had a previous traffic accident. This group also comprised a greater proportion of persons with cardiovascular problems before the accident (Table 1). 
Table 1: Characterization of the study population taking into account the response to the question about feelings.

\begin{tabular}{|c|c|c|c|}
\hline Variables & $\begin{array}{l}\text { Respondents } \\
(\mathrm{n}=626)\end{array}$ & $\begin{array}{l}\text { Non- } \\
\text { respondents } \\
(\mathrm{n}=\mathbf{1 2 5})\end{array}$ & p-value \\
\hline Age at time of accident (mean, s.d.) & $34.9(15.5)$ & $40.6(17.6)$ & $<.001$ \\
\hline Proportion of women $(\%)$ & 40.7 & 42.4 & ns \\
\hline Proportion of M-AIS $\geq 3(\%)$ & 24.6 & 40.8 & $<.001$ \\
\hline M-AIS low. limbs $\geq 3$ & 12.6 & 20.8 & $<.05$ \\
\hline M-AIS up. limbs $\geq 3$ & 4.8 & 10.4 & $<.05$ \\
\hline NISS (mean, s.d.) & $7.9(9.9)$ & $10.9(11.3)$ & $<.01$ \\
\hline Cardiovascular disorders background (\%) & 1.6 & 4.8 & $<.05$ \\
\hline Previous traffic accident $(\%)$ & 33.6 & 48 & $<.01$ \\
\hline \multicolumn{4}{|l|}{ Post-traumatic stress (PCLS) (mean, s.d.) } \\
\hline Avarage score & $30(14)$ & $29.9(13.6)$ & ns ) \\
\hline re-experiencing scale & $9.1(4.8)$ & $9(4.8)$ & ns \\
\hline avoidance scale & $11.3(5.6)$ & $11.1(5.3)$ & ns \\
\hline hyperarousal scale & $9.6(5.4)$ & $9.8(5.3)$ & ns \\
\hline \multicolumn{4}{|l|}{ QoL (WHOQOL-bref) (mean, s.d.) } \\
\hline overall QoL & $3.7(0.9)$ & $3.7(0.8)$ & ns \\
\hline health satisfaction & $3.4(1.1)$ & $3.2(1.1)$ & ns \\
\hline physical health & $71.1(19.8)$ & $70.7(19.8)$ & ns \\
\hline psychological & $64.9(17)$ & $63.9(17)$ & $\mathrm{ns}$ \\
\hline social relationships & & $71.8(15.8)$ & ns \\
\hline environment & $65.3(17)$ & $68.1(15.8)$ & ns \\
\hline Word(s) count used (mean, s.d.) & $13.1(11.1)$ & $\mathbf{0}(\mathbf{0})$ & $<.001$ \\
\hline Emotional word(s) count used (mean, s.c & $0.9(1)$ & $\mathbf{0}(\mathbf{0})$ & $<.001$ \\
\hline
\end{tabular}

Among the 626 respondents, 328 (52.4\%) expressed emotional experiences in their verbatim accounts. The significant differences between the group expressing emotional experiences and the group who did not $(\mathrm{n}=298)$ were mainly for the variables QoL (WHOQOL) and PTSD (PCLS), indicating better psychological wellbeing in the second group. Members of this group tended to be male, were younger, and used far fewer words in their responses. Moreover, this group also comprised a lower proportion of persons who had severe injuries (M-AIS $\geq 3$ ), as confirmed by comparing the NISS values (Table 2). 
Table 2: Characteristics of respondents without or with emotional experience and according to the valence of emotional experience expressed.

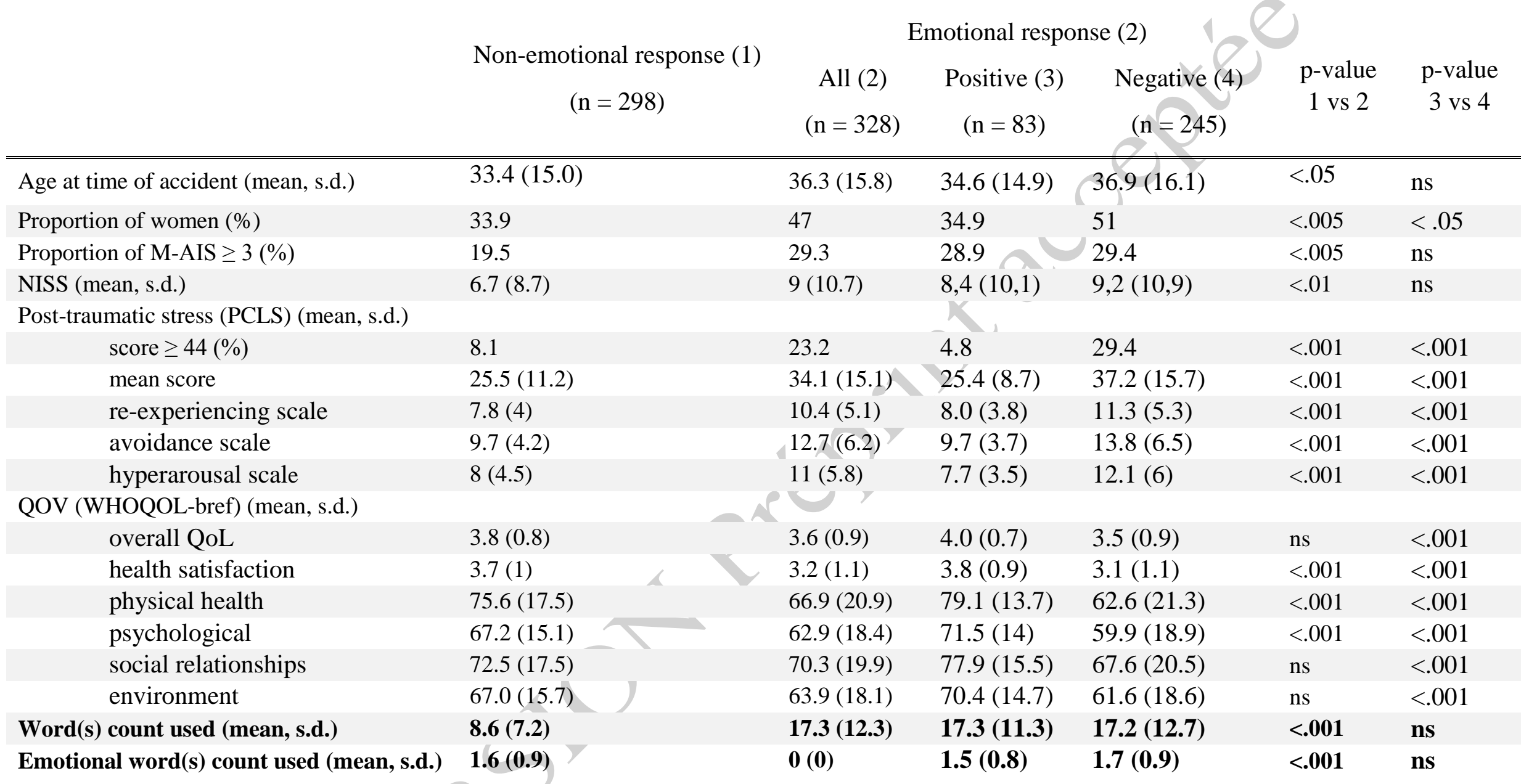




\section{Hierarchical classification.}

The hierarchical clustering analysis was carried out on the 328 subjects expressing emotional experiences, based on the eighteen emotional themes of the intermediate level and the two valence variables. Three cut-off levels (A: two "sets", B: three "aggregations" and C: nine "groups") on the similarity tree were considered (figure 5 in Appendix). Each of these cut-off levels enabled us to refine the characterization of individuals in the studied population.

\section{Comparison between negative and positive emotion sets (Cut-off level A).}

The main distinguishing characteristic of the two sets was the valence of the expressed emotional experiences, both in terms of negative valence emotional expression $(5.7 \%$ for the set expressing positive emotions; $\mathrm{Z}=-12, \mathrm{p}<.001)$ and of positive valence emotional expression (92.7\% for the set expressing positive emotional experiences $Z=-17, p<.001)$. Among the 328 persons expressing an emotional experience in their response, 245 (74.7\%) expressed one or more negative emotions. Subjects expressing positive valence emotional experiences were more often male, with better self-assessed QoL and overall showed fewer signs of PTSD than subjects expressing negative valence emotional experiences (Table 2).

\section{Comparison of the three aggregations (cut-off B)}

The cut-off level B differentiated the 245 persons expressing an emotional experience of negative valence in two distinctive aggregations. Aggregation I (moderate number of emotional experiences of negative valence, $n=167$ ) differed significantly from aggregation II (high number of negative emotional experiences, $n=78$ ) on the mean number of expressions of negative emotional experiences $(1.19$ versus $2.59 ; \mathrm{F}(1,245)=286.65, \mathrm{p}<.001)$, of feelings of fear $(0.09$ versus 0.31 ; $\mathrm{F}(1,245)=17.9, \mathrm{p}<.001)$, of anxiety $(0.10$ versus $0.28 ; \mathrm{F}(1,245)=10.13, \mathrm{p}<.01)$, of suffering $(0.19$ versus $0.47 ; \mathrm{F}(1,245)=19.69, \mathrm{p}<.001)$ and of depression $(0.07$ versus $0.41 ; \mathrm{F}(1,245)=$ $32.16, \mathrm{p}<.001)$. Only the negative feelings of distress and frustration showed homogeneity between the two aggregations expressing emotional experiences of negative valence.

The two negative aggregations were distinguished by their PTSD (figure 2) evaluation, except for the re-experience component of PTSD. In terms of QoL (figure 3), they differed by their health satisfaction supported by the observed differences in the physical and psychological domains (Table 3). These two aggregations were furthermore differentiated by the gender (moderate [I]: $46.3 \%$ vs high [II]: $60.3 \%, \mathrm{p}<0.05)$ the severity of the initial lesions $(24.0 \%$ vs $41 \%, \mathrm{p}<0.001)$, particularly of the lower extremities, and the greater proportion of participants with medical history [hypertension (moderate [I]: 4.8\% vs high [II]: 12.8\%); daily life accidents $(7.2 \%$ vs $16.7 \%$ ), 
osteopathic problems (17.4\% vs $35.9 \%)$ and a lesser proportion of participants reporting a positive event prior to the accident in aggregation II (1.3\% vs $13 \%$ in aggregation I). Moreover, the participants in aggregation II were older. They also employed a greater number of words in their response and expressed a greater number of emotional experiences.

Table 3: Characteristics of the two aggregations with negative emotions

\begin{tabular}{|c|c|c|c|}
\hline Variable & $\begin{array}{l}\text { Moderate negative } \\
\text { emotions } \\
(\mathrm{n}=167) \\
\text { Agg I }\end{array}$ & $\begin{array}{l}\text { High negative } \\
\text { emotions } \\
(\mathbf{n}=78) \\
\text { Agg II }\end{array}$ & $\mathbf{P} *$ \\
\hline Age at time of accident: mean (s.d.) & $34.4(14.1)$ & $42.1(18.8)$ & $<.005$ \\
\hline \multicolumn{4}{|l|}{ Post-traumatic stress (PCLS) } \\
\hline score $\geq 44(\%)$ & 24.0 & 41.0 & 0,004 \\
\hline mean score: mean (s.d.) & $37.2(15.5)$ & $41.6(15.5)$ & $<.005$ \\
\hline re-experiencing score: mean, (s.d.) & $10.8(5.2)$ & $12.4(5.3)$ & ns \\
\hline avoidance score: mean, (s.d.) & $13.2(6.5)$ & $15.2(6.4)$ & $<.05$ \\
\hline hyperarousal score: mean, (s.d.) & $11.3(5.9)$ & $14(6.0)$ & $<.005$ \\
\hline \multicolumn{4}{|l|}{ QOL (WHOQOL-bref) mean (s.d.) } \\
\hline overall QoL & $3.5(0.9)$ & & ns \\
\hline health satisfaction & $3.2(1.1)$ & $2.7(1.1)$ & $<.005$ \\
\hline physical health & $65.2(21.1)$ & $56.8(20.9)$ & $<.01$ \\
\hline Psychological & $62.2(18.1)$ & $54.7(19.7)$ & $<.01$ \\
\hline social relationships & $68.4(21.2)$ & $65.9(19.1)$ & ns \\
\hline Environment & $61.3(19.5)$ & $62.2(16.4)$ & ns \\
\hline Word(s) count used mean (s.d.) & $13.9(11.3)$ & $24.3(12.7)$ & $<.001$ \\
\hline Emotional word(s) count used (mean, s.d.) & $1.2(0.5)$ & $2.6(0.9)$ & $<.001$ \\
\hline
\end{tabular}

* Bonferroni correction

Aggregation III consisted of persons expressing one or more positive emotional experiences described in the preceding paragraph; they differed from the two other aggregations by PTSD and a better QOL (figures $2 \& 3$ ).

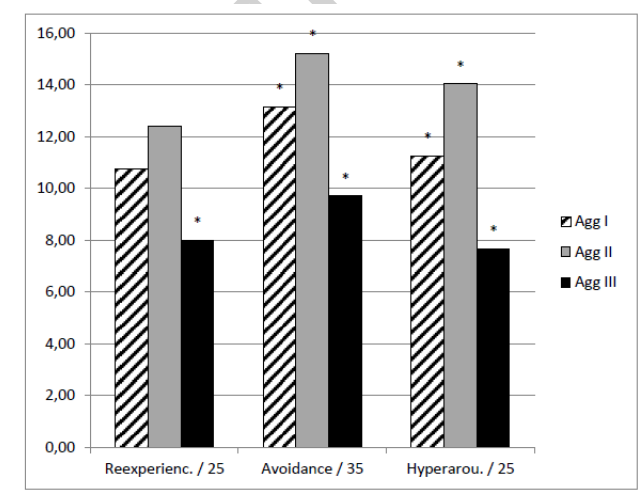

Figure 2: Mean scores of aggregations I, II and III for the three sub-components of PTSD Figure 2:

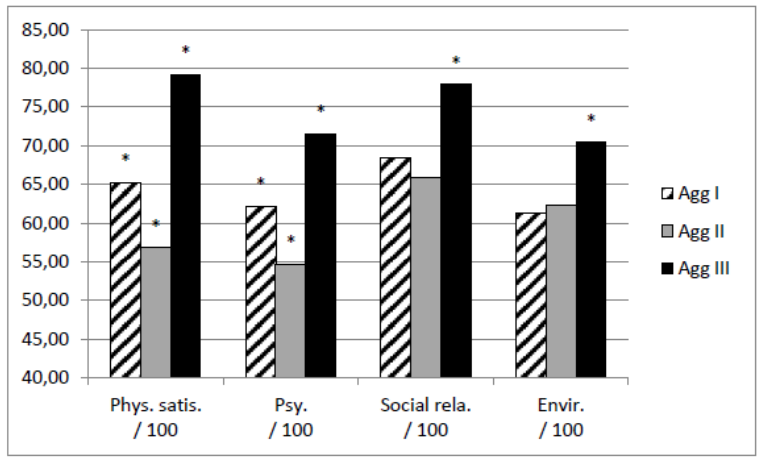

Figure 3: Mean scores of aggregations I, II and III for four components of the QoL (WHOQOL-bref)

The asterisks (*) indicate a significant difference with each of the two other aggregations after Bonferroni Correction $\mathrm{p}<.01$. 
The third cut-off gives 9 groups: their main significant differences are summarized below. Table 4 shows the significant characteristics of the nine groups, compared to the whole group.

Aggregation I sub-divided into four groups:

$\checkmark$ Group 1 (12.8\% of the population): expression of problems (upset and remorse). One third of the subjects of this group suffered serious injury (M-AIS $\geq 3$ ), with moderate psychological impact (PCLS, WHOQOL).

$\checkmark$ Group 3 (22\%): moderate expression of anxiety and hostility. A quarter of the subjects of this group suffered serious injury, with moderate psychological impact.

$\checkmark$ Group $6(6.7 \%)$ : expression of frustration. 18.2\% of the subjects of this group suffered serious injury, with weak psychological impact, and only $4.5 \%$ showed history of osteopathic problems and only $13.8 \%$ had recourse to one or more psychological consultations before the accident.

$\checkmark$ Group 8 (9.4\%): expression of suffering. 12.9\% suffered serious injuries differentiating them from members of groups 1,2, 4, and 5, and notably none of them had serious injury to the spine or lower limbs. They had moderate psychological impact.

Aggregation II sub-divided into three groups:

$\checkmark$ Group 2 (11.6\%): expression of suffering, depression and distress. This group differed from groups 3, 6, 8 and 9 in the high percentage $(44.7 \%)$ of subjects with serious injuries, principally of the lower limbs. These subjects were strongly impacted psychologically, particularly in QoL in the physical and health domains. 39.5\% displayed osteopathic problems before the accident. On average, they were older than the members of groups 3,8 and 9 . Finally, only $28.9 \%$ had high-school leaving certificates, which differentiated them from groups $1,3,5$ and 7 .

$\checkmark$ Group 4 (5.8\%): expression of hostility, discontent and fear. $47.4 \%$ of the subjects in this group suffered severe wounds, which differentiated them from groups 6, 8, 9. There were remarkably high proportions of serious injuries to the head, spine and thorax, indicating a high rate of multiple trauma. Comparison of NISS scores provides only weak confirmation of this fact, the only difference found being with group 9. Members of group 4 had strong psychological impact, $52.6 \%$ having a score of at least 44 on the PCLS, which differentiated them from all the other groups, especially in the hyper-vigilance dimension of PTSD. $42.1 \%$ had osteopathic problems before the accident, and 52.6\% had recourse to one or more psychological consultations prior to the accident. Finally, they expressed an average 3.7 emotional experiences, which differentiated them from all other groups. 
$\checkmark$ Group 7 (6.4\%): expression of anxiety. $28.6 \%$ of the subjects of this group suffered serious injury. They had moderate psychological impact, although one third exceeded the threshold of 44 on the PCLS. It is noteworthy that the group comprised two thirds females and that $19 \%$ of members suffered from arterial hypertension before the accident.

Aggregation III sub-divided into two groups:

$\checkmark$ Group 5 (16.8\%): expression of wellbeing and goodwill. $40 \%$ of subjects in this group suffered serious injury, a rate equivalent to groups 2 and 4 , but which differentiated them from groups 8 and 9. They were not psychologically impacted in terms of PTSD or QoL, both of which they judged excellent in every domain.

$\checkmark$ Group 9 (8.5\%): expression of calm. Only $7.1 \%$ of subjects in this group suffered serious injury, which differentiated them from groups 1, 2, 3, 4, 5 and 7 (figure 4). They had no psychological impact in terms of QoL, and their PCLS scores were extremely low and never exceeded the threshold of 44 . It is noteworthy that this group comprised only $25 \%$ of females, which differentiated it from groups 2, 3, 4 and 7. 
Table 4: Proportional and mean characteristics of the nine groups, and the whole group

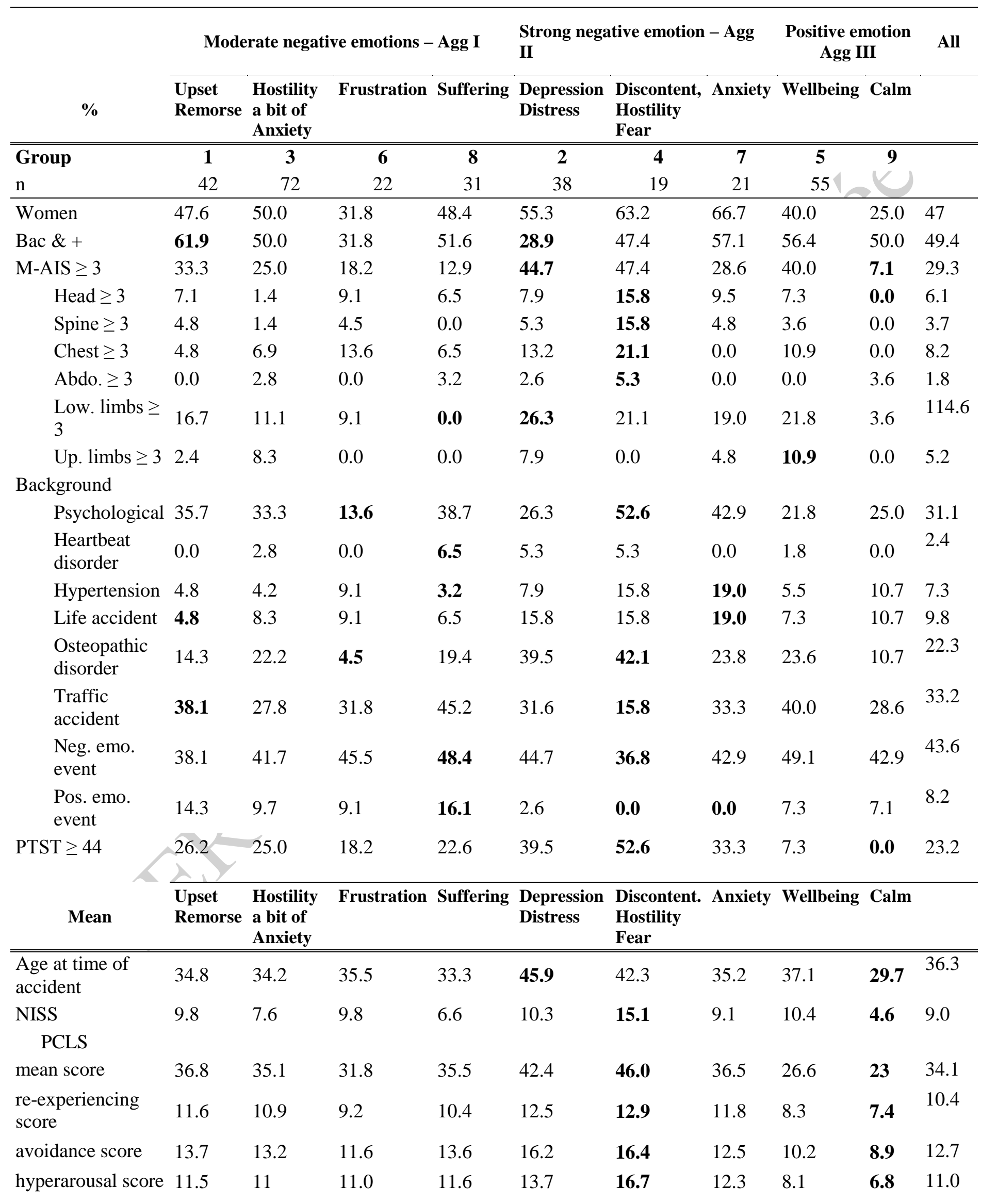


Moderate negative emotions - Agg I
Strong negative emotion - Agg II
Positive emotion

Agg III

\section{WHOQOL-}

bref

overall QoL 3.6

health satisfaction 3.3

physical health

psychological

68.2

65.2

66.7

62.0

11.0

$14.6 \quad 14.9$

11.0

Emotional word(s) count used

1.5

$1.1 \quad 1.4 \quad 1.0$

3.43.

\section{3}

3

2.3

3.4

$$
3.7
$$

$3.2 \quad 3.7$

$4 \quad 3.6$

60.5

50.3

3.1

$68.6 \quad 78.7$

$3.9 \quad 3.2$

57.1

53.7

56.3

$56 \quad \mathbf{7 4 . 2}$

79.966 .9

55.4

60.8 64.8

66.7

$67.1 \quad \mathbf{7 8 . 7}$

$66.2 \quad 62.9$

60.4

59.6

66.7

$62.9 \quad \mathbf{7 2 . 3}$

$66.8 \quad 63.9$

12.9

20.9

29.2

26.0

20.4

$11.1 \quad 17.3$

1.5

2.3

3.7

2.4

1.7

1.1

1.6




\section{Discussion}

Our study aimed to characterize different possible profiles of emotional experiences of victims of traffic accident based on verbatim accounts collected one year after the accident. Injury severity and history distinguished two sets expressing negative-valence emotional experience. These profiles were then linked to socio-demographic and health data. A relation appeared between quality of life (QoL), post-traumatic stress disorder (PTSD) and the valence of emotions expressed by victims one year after their traffic accident. Expression of emotional experiences of positive valence was associated with low assessments of PTSD and good self-assessments of QoL.

\section{Categorization of emotional experiences}

Among the 751 participants of the ESPARR cohort able to respond to the question about feelings, 125 (16.6\% of the sample) avoided doing so. Non-respondents to this question showed a higher proportion of seriously wounded and are elderly than respondents, regardless of gender. It is noteworthy that they replied to all the other parts of the one-year questionnaire. This question impinges on a realm of intimacy, concerning as it does a 'tipping point' after which, for the most severely injured, their position in their own environment and their life-projects were never the same again (Mayou \& Bryant, 2003). Avoiding the expression of emotional experiences can be understood as a difficulty to express feelings that are still too vivid. The higher NISS scores of these 'non-respondents,' a sign of multiple traumas, support this proposal but is not coherent with the absence of difference for PTSD scores and Quality of life between respondents and nonrespondents.

Not all respondents expressed an emotional experience. Those who did not so were more frequently males, suffering from less severe injuries. Their self-evaluation showed them to be more satisfied in terms of QoL and less affected by PTSD. This result contradicts previous work that showed an association between the persistence of PTSD and emotional inhibition (Holeva \& al., 2001; Bryant, 2011). One approach to explain this contradiction lies in the concept of emotional granularity (Feldman-Barrett; 2006; Russell \& Feldman-Barrett, 1999). According to the authors, a high level of emotional granularity is associated with a detailed description of feeling, and ability for fine and precise categorization. Conversely, broad and general description, and poor ability to categorize feelings corresponds to a low level of emotional granularity. Thus, knowing how to describe an emotional experience requires on the one hand substantial mastery of language, and on the other, excellent abilities to discriminate feelings, and these are aptitudes not easily acquired. 
Injury severity would expect to influence the expression of emotional experiences, notably their positive or negative valence. The two groups (valence of positive and negative feelings) differed from each other on health status variables (QoL and PTSD) without differentiation when it comes to the seriousness of the injuries. Thus an interrelation appeared between the valence of the expressed feelings and all components of QoL and PTSD. This result tallies with those of a study that found QoL depended more on socio-demographic variables (such as living alone, or incapacity to work) than on the gravity of the lesions or time spent in medical care and rehabilitation (van Delft-Schreurs et al., 2014). Moreover, we would expect serious head injuries to influence expression of emotional experiences numbed by brain trauma (Bryant, 2011). This did not appear in our sample, however, posing the question of differential diagnosis between brain injury and PTSD. The activation dimension, or degree of arousal ranging from calm to excitement, is included in numerous study tools, such as the Geneva Emotion Wheel that measures the intensity of emotions (Sacharin \& al, 2012), and the Russell \& Feldman-Barrett model, which focuses on the excitation component of the core affect (Russell \& Feldman-Barrett, 1999). Activation is highlighted in our study by the cut-off levels B and C. Our results suggest that the activation level varies from one type of emotional experience to another. Feelings corresponding to anxiety (group 7), and those expressing hostility, discontent and fear (group 4), or depression and suffering (group 2), are endowed with greater activation than all the other feelings expressing emotional experiences of negative valence. Indeed, persons in these groups (aggregation II) differed from those forming aggregation I (moderate number of negative emotional experiences expressed) by exhibiting a greater proportion of seriously injured persons, higher PTSD scores, poorer score in self-assessed QoL and higher rates of medical history. Correspondingly, few reported a positive event before the accident (1.3\%).

Comparing two sub-groups derived from aggregation III (expression of positive emotional experiences), we can extend, through symmetry, this difference in activation for emotional experiences of positive valence. Whereas group 9 (expression of calm) stood out for being the least impacted by the accident (physically, psychologically and in terms of history), group 5 (expression of wellbeing and well-wishing) showed a proportion of seriously injured (M-AIS $\geq 3$ ) victims similar to that of groups 2 and 4, the most impacted by the accident at all levels. Even so, group 5 victims expressed positive emotional experiences and their assessments for PTSD and QoL showed a high standard of psycho-social adaptation.

A counter-intuitive profile emerged from the results: group 5 combined a high rate of severe injury associated with the expression of psychological wellbeing (PTSD, WHOQOL) and feelings of positive valence. Thus, if the subjects are optimistic about their future, if they relativize their accident, if they think they have been "lucky" - a word repeated 48 times in the verbatim accounts - 
they may express emotional experiences of positive valence, confirmed by the self-assessments of QoL and PTSD. At the same time they have suffered serious injuries, as was the case with a large proportion $(40 \%)$ of the victims of group 5. Feldman-Barrett (2006) suggests that emotional experiences are constructed by an act of categorization, and asserts that acquired knowledge determines our points of view, our way of seeing and of feeling. This introduces a circular causality (Bertalanffy, 1968; Maturana \& Varela, 1987; Varela et al., 1991) that guides clinical practice. Indeed, the data of group 5 suggested that expressing feelings increases happiness (bliss, joy, laughter), spirit (gaiety, liveliness, arousal), relief (soothing, release), and affection (love, desire, admiration, attraction), as factors that provide protection in dealing with the consequences of a traffic accident. By contrast, expression of suffering (weeping, pain, tears), as found in members of group 8 , may be an aggravating factor, considering the low rate of severe injury in this group.

\section{Emotional experiences: a therapeutic lever}

These results deserve careful consideration in terms of their application in providing care for traffic accident victims. Group 5, reflecting a psychosocial adaptation in spite of a high rate of serious injury, showed that expressing feelings could be related to resilience (Dufour et al., 2000). Reviving the traumatic event in debriefing or imaginary re-experience (Brillon et al., 1996; Bryant, 2011) or by writing (Sloan $\&$ al., 2012) are practices that have proved effective in treating PTSD. It appears that early intervention, in the hours following the traumatic event, may be advisable in order to mitigate the negative consequences of exposure to trauma (Kearns et al., 2012; Matuseviciene et al., 2015). In line with this idea, and the emotional experiences expressed by group 5, reframing the emotional situation may be an interesting tool (Schaefer et al., 2013). Reframing basically consists in altering the context of a situation with the aim of changing completely the meaning. In order to be accepted, reframing must appear culturally plausible to whomever it is suggested and is only of use if it offers an alternative reading of the situation, if it opens up other possibilities (Watzlavick et al, 1967, 1974). Hypnosis is recognized as an "operational means of reframing by which the entire behaviour of the subject is reframed as other" (Melchior, 2002) and can be of use in enabling traffic accident victims to express their pessimism, imbued with emotional experiences of negative valence, immediately after the accident.

Our results also carry a possible lesson for the planning of social support. Expression of negative valence emotional experiences showed a low level of satisfaction in the social and environmental areas of QoL while differing in the physical and psychological domains. Yet it is widely recognized that perceived social support, which is one dimension of the social network, is as much a factor of psychological as of physical resilience (Barrera \& Ainley, 1983; Dufour et al., 2000; Holeva et al., 2001; Mitchell \& Trickett, 1980; Robinaugh et al., 2011). It seems important to 
take into account family members, to integrate them into the care process, for example through therapeutic education on the psychological consequences of PTSD or a traffic accident, with the aim of enabling them to respond to their kin in an adaptive manner and thereby join his or her social support team. The work of reframing with the victim, based upon re-discussion within the family circle of the ties of attachment, can prove useful in making the victim aware of his or her social network, while feeling cared for and supported (Erickson \& Rossi, 1978).

Other therapeutic treatments could be proposed such as mindfulness-based cognitive therapy (MBCT), which acts as a training to improve the emotional granularity, could prevent the risk of depressive relapse (subjects in subgroups 1 and 2) (Kuyken et al. 2016, Piet et Hougaard, 2001, Van der Velden, 2015). While taking into account the expression of emotions, the EMDR technique (Eye Movement Desensitization and Reprocessing) gives good results in the care of adult PTSD (Shapiro, 2001, 2014). It has also been shown that EMDR and hypnosis can be combined as a therapeutic approach for dissociative disorders, amplifying the clinical effectiveness. In 2013, WHO warned against some common treatments, such as the administration of benzodiazepine to reduce acute symptoms of post-traumatic stress (World Health Organization, 2013).

\section{Strengths and limitations}

To our knowledge, the question of emotional experiences one year after a traffic accident has never been studied on such a large population with a prospective follow-up. The results therefore are particularly interesting for developing knowledge of accident victims who suffer prolonged multiple consequences and for considering how to improve the targeting of early therapeutic intervention. Several limitations are apparent, however. Non-respondents are described as young men with minor injuries which is usual (Nhac-Vu et al., 2014; Tivesten et al., 2012, van Delft-Schreur, 2014). However, this could call into question the possibility of generalizing our results to the general population.

Among the entirety of verbatim accounts contained in the ESPARR cohort questionnaires, we restricted ourselves to those that referred to a specific open question. Several other written records were ignored, which implies an obvious loss of data. Furthermore, the dominance component (control - non-control) could not be taken into account, as the verbatim accounts were too short to extract from them a satisfactory linguistic analysis.

The methodology also suffered from non-response, notably for the QoL and PTSD variables. Nevertheless, incomplete questionnaires, even in the worst cases (PTSD), only concern $5 \%$ of respondents, which should have little impact on the results. 


\section{Conclusion}

Distinctive profiles of emotional experiences from the verbatim accounts of victims one year after their traffic accident were find. A counter-intuitive result was brought to light, in that members of group 5, who expressed emotional experiences of positive valence confirmed by psychological wellbeing (high QoL and low symptomatology of PTSD), also suffered serious injuries during the accident event. Our approach improved understanding of the emotional experiences of traffic accident victims, thus enabling the provision of care to be systematically directed toward psychological management of traffic accident victims arriving in health-care structures, furthering remission and promoting their psychological wellbeing. Consideration of emotional experiences as stratagems adapted to coping with environmental stress led us into the field of psychosocial adaptation of survivors of traffic accidents. This is a vast field, encompassing not only rehabilitation, ergonomics and cognitive science, but also the political and economic dimensions, which influences social organization and integration of disabled members of the community.

\section{Funding}

We acknowledge funding from the French Ministry of Equipment, Transport, Housing, Tourism and Sea (Predit 3 Program, "New Knowledge in the Field of Road Safety": N ${ }^{\circ}$ SU0400066), from the National Agency for Research (Program Predit 4 "Safe, reliable and adapted transport" No. ANR-07-TSFA-007-01) and from the French Ministry of Health (PHRC 2003 Program: PHRC-N03 and PHRC 2005: PHRC- N051).

\section{Conflict of interest}

The individual authors have no competing interests to declare.

\section{Acknowledgments}

The authors are grateful to the victims for their cooperation in data collection. The authors would like to thank all those who assisted in carrying out this study: Nadia Baguena, Jean Yves Bar, Amélie Boulanger, Elodie Paquelet, Stuart Nash and Véronique Sotton for collecting the data, and Irène Vergnes for organizing the databases; Anne-Marie Bigot, Nathalie Demangel and Geneviève Boissier for subject database management; Amina Ndiaye and the Association for the Rhône Road Trauma Registry (ARVAC) for their help in collecting and providing medical data; the Scientific 
Committee (Jean-Louis Martin, Daniel Floret, Etienne Javouhey, Jacques Gaucher, Jacques Luauté and Dominique Boisson); all the hospital staff who accepted the interviewers' presence and who referred victims; and the SAMU medical ambulance team who reported their daily emergency interventions, all the UMRESTTE team for advice and assistance; Laurie Mondillon for these valuable tips on therapeutic care. Special thanks to Iain McGill and Neil Dewhurst for comments and manuscript editing.

\section{References}

Amoros, E., Martin, J.-L., \& Laumon, B. (2008). Estimation de la morbidité routière, France, 19962004. Bulletin épidémiologique hebdomadaire, 19, 157-160.

Association for the Advancement of Automotive Medicine (AAAM). (1990). The abbreviated Injury Scale (AIS), 1990 révision. Des Plaines, II, USA : AAAM.

Barrera, M., \& Ainlay, S. L. (1983). The structure of social support: a conceptual and empirical analysis. Journal of community psychology, 11(2), 133-143.

Bertalanffy, L. von. (1968). General system theory: foundations, development, applications. New York: Braziller.

Blanchard, E. B., Hickling, E. J., Taylor, A. E., \& Loos, W. (1995). Psychiatric morbidity associated with motor vehicle accidents. The Journal of nervous and mental disease, 183(8), 495-504.

Blanchard, E. B., Jones-Alexander, J., Buckley, T. C., \& Forneris, C. A. (1996). Psychometric properties of the PTSD Checklist (PCL). Behaviour research and therapy, 34(8), 669-673.

Bradley, M. M., \& Lang, P. J. (1994). Measuring emotion: the self-assessment manikin and the semantic differential. Journal of Behavior Therapy and Experimental Psychiatry, 25(1), 49-59.

Brewin, C. R., \& Holmes, E. A. (2003). Psychological theories of posttraumatic stress disorder. Post Traumatic Stress Disorder, 23(3), 339-376.

Brillon, P., Marchand, A., \& Stephenson, R. (1996). Modèles comportementaux et cognitifs du trouble de stress post-traumatique. Santé mentale au Québec, 21(1), 129-144.

Bryant, R. (2011). Post-traumatic stress disorder vs traumatic brain injury. Dialogues in clinical neuroscience, 13(3), 251-262.

Chossegros, L., Hours, M., Charnay, P., Bernard, M., Fort, E., Boisson, D., ... Laumon, B. (2011). Predictive factors of chronic post-traumatic stress disorder 6 months after a road traffic accident. Accident Analysis \& Prevention, 43(1), 471-477.

Christensen, M. C., Banner, C., Lefering, R., Vallejo-Torres, L., \& Morris, S. (2011). Quality of life after severe trauma: results from the global trauma trial with recombinant factor VII. The Journal of Trauma-Injury Infection \& Critical Care, 70(6), 1524-1531.

Dalgleish, T. (2004). The emotional brain. Nature Reviews Neuroscience, 5(7), 583-589.

Davydow, D. S., Zatzick, D. F., Rivara, F. P., Jurkovich, G. J., Wang, J., Roy-Byrne, P. P., ... MacKenzie, E. J. (2009). Predictors of posttraumatic stress disorder and return to usual major activity in traumatically injured intensive care unit survivors. General Hospital Psychiatry, $31(5), 428-435$. 
Dufour, M. H., Nadeau, L., \& Bertrand, K. (2000). Les facteurs de résilience chez les victimes d'abus sexuel : état de la question. Child Abuse \& Neglect, 24(6), 781-797.

Ehlers, A., Mayou, R. A., \& Bryant, B. (1998). Psychological predictors of chronic posttraumatic stress disorder after motor vehicle accidents. Journal of Abnormal Psychology, 107(3), 508-519.

Erickson, M. H., \& Rossi, E. L. (1989). The February man: evolving consciousness and identity in hypnotherapy. New-York: Brunner - Mazel.

Feldman-Barrett, L. (2006). Solving the emotion paradox: categorization and the experience of emotion. Personality and social psychology review, 10(1), 20-46.

Feldman-Barrett, L., Lindquist, K. A., \& Gendron, M. (2007). Language as context for the perception of emotion. Trends in cognitive sciences, 11(8), 327-332.

Fine, C. G. and A. S. Berkowitz (2001). The wreathing protocol: the imbrication of hypnosis and EMDR in the treatment of dissociative identity disorder and other dissociative responses. Eye Movement Desensitization Reprocessing. Am J Clin Hypn 43(3-4): 275-90.

Frischholz, E. J., J. A. Kowal, et al. (2001). Introduction to the special section: hypnosis and EMDR. Eye Movement Desensitization and Reprocessing. Am J Clin Hypn 43(3-4): 179-82.

Fort, E., Bouffard, E., Charnay, P., Bernard, M., Boisson, D., Laumon, B., \& Hours, M. (2011). Return to work following road accidents: factors associated with late work resumption. Journal of Rehabilitation medicine, 43(4), 283-291.

Gil, S. (2009). Comment étudier les émotions en laboratoire. Revue électronique de psychologie sociale, 4, 15-24.

Hendrick, S. (2002). Les émotions exprimées. Cahiers critiques de thérapie familiale et de pratiques de réseaux, (29), 139-166.

Holeva, V., Tarrier, N., \& Wells, A. (2001). Prevalence and predictors of acute stress disorder and PTSD following road traffic accidents: Thought control strategies and social support. Behavior Therapy, 32(1), 65-83.

Hours, M., Bernard, M., Charnay, P., Chossegros, L., Javouhey, E., Fort, E., Boisson D., Sancho, P.-O., Laumon, B. (2010). Functional outcome after road-crash injury: Description of the ESPARR victims cohort and 6-month follow-up results. Accident Analysis \& Prevention, 42(2), 412-421.

Hours, M., Chossegros, L., Charnay, P., Tardy, H., Nhac-Vu, H.-T., Boisson, D., ... Laumon, B. (2013). Outcomes one year after a road accident: Results from the ESPARR cohort. Accident Analysis \& Prevention, 50, 92-102.

Jones, C., Harvey, A. G., \& Brewin, C. R. (2007). The organisation and content of trauma memories in survivors of road traffic accidents. Behaviour Research and Therapy, 45(1), 151-162.

Kearns, M. C., Ressler, K. J., Zatzick, D., \& Rothbaum, B. O. (2012). Early interventions for PTSD: a review. Depression and Anxiety, 29(10), 833-842.

Khati, I. M. Hours, Charnay P, Chossegros L, Tardy H, Nhac-Vu H-T, Boisson D \& Laumon B (2013). Quality of life 1 year after a road accident: Results from the adult ESPARR cohort. Journal of trauma and acute care surgery 74(1): 301-311

Kuyken, W., Warren, F. C., Taylor, R. S., Whalley, B., Crane, C., Bondolfi, G., ... \& Segal, Z. (2016). Efficacy of mindfulness-based cognitive therapy in prevention of depressive relapse: An individual patient data meta-analysis from randomized trials. JAMA psychiatry, 73(6), 565-574. 
Maturana, H. R., \& Varela, F. J. (1987). The tree of knowledge: the biological roots of human understanding. Boston, Mass.: Shambhala press.

Matuseviciene, G., Eriksson, G., \& Nygren DeBroussard, C. (2015). No effect of an early intervention after mild traumatic brain injury on activity and participation: a randomized controlled trial. Journal of rehabilitation medicine, 47, 1-8.

Mayou, R., \& Bryant, B. (2003). Consequences of road traffic accidents for different types of road user. Injury, 34(3), 197-202.

Melchior, T. (2002). Communication hypnotique, symptômes et émotions. Cahiers critiques de thérapie familiale et de pratiques de réseaux, 29(2), 123.

Minsky, M. (1986). The Society of Mind. New York: Simon \& Schuster.

Minsky, M. (2006). The emotion machine. New York: Pantheon.

Mitchell, R. E., \& Trickett, E. J. (1980). Task force report: social networks as mediators of social support. Community mental health journal, 16(1), 27-44.

Murray, J., Ehlers, A., \& Mayou, R. A. (2002). Dissociation and post-traumatic stress disorder: two prospective studies of road traffic accident survivors. The British Journal of Psychiatry, 180(4), 363-368.

Nhac-Vu, H.-T., Hours, M., Chossegros, L., Charnay, P., Tardy, H., Martin, J.-L., ... Laumon, B. (2014). Prognosis of outcome in adult survivors of road accidents in France : one-year followup in the ESPARR cohort. Traffic Injury Prevention, 15(2), 138-147.

Phillips, M. (2001). Potential contributions of hypnosis to ego-strengthening procedures in EMDR. Eye Movement Desensitization Reprocessing. Am J Clin Hypn 43(3-4): 247-62.

Piet, J., \& Hougaard, E. (2011). The effect of mindfulness-based cognitive therapy for prevention of relapse in recurrent major depressive disorder: A systematic review and meta-analysis. Clinical Psychology Review, 31(6), 1032-1040.

Piolat, A., \& Bannour, R. (2009). EMOTAIX: un scénario de Tropes pour l'identification automatisée du lexique émotionnel et affectif. L'Année psychologique, 109(04), 655-698.

Rabe, S., Zöllner, T., Maercker, A., \& Karl, A. (2006). Neural correlates of posttraumatic growth after severe motor vehicle accidents. Journal of Consulting and Clinical Psychology, 74(5), 880-886.

Robinaugh, D. J., Marques, L., Traeger, L. N., Marks, E. H., Sung, S. C., Gayle Beck, J., ... Simon, N. M. (2011). Understanding the relationship of perceived social support to post-trauma cognitions and posttraumatic stress disorder. Journal of Anxiety Disorders, 25(8), 1072-1078.

Russell, J. A. (2009). Emotion, core affect, and psychological construction. Cognition and Emotion, $23(7), 1259-1283$.

Russell, J. A., \& Feldman-Barrett, L. (1999). Core affect, prototypical emotional episodes, and other things called emotion: dissecting the elephant. Journal of personality and social psychology, 76(5), 805-819.

Sacharin, V., Sander, D., \& Scherer, K. R. (2012). The perception of changing emotion expressions. Cognition \& emotion, 26(7), 1273-1300.

Sampalis, J. S., Liberman, M., Davis, L., Angelopoulos, J., Longo, N., Joch, Sampalis, F., Nikolis, A., M., Lavoie, A., Denis, R., Mulder, D. S. (2006). Functional Status and Quality of Life in Survivors of Injury Treated at Tertiary Trauma Centers: What Are We Neglecting? Journal of Trauma-Injury Infection \& Critical Care, 60(4), 806-813. 
Schaefer, S. M., Boylan, J. M., van Reekum, C. M., Lapate, R. C., Norris, C. J., Ryff, C. D., \& Davidson, R. J. (2013). Purpose in life predicts better emotional recovery from negative stimuli. Plos One, 8(11), 1-9.

Scherer, K. R. (2005). What are emotions? And how can they be measured? Social Science Information, 44(4), 695-729.

Shapiro, F. (2001). Eye Movement Desensitization and Reprocessing: Basic Principles, Protocols, and Procedures., Guildford Press. Shapiro, F. and M. S. Forrest (2004).

Shapiro, F. (2014). The role of eye movement desensitization and reprocessing (EMDR) therapy in medicine: addressing the psychological and physical symptoms stemming from adverse life experiences. Perm J 18(1): 71-7.

Sloan, D. M., Marx, B. P., Bovin, M. J., Feinstein, B. A., \& Gallagher, M. W. (2012). Written exposure as an intervention for PTSD: a randomized clinical trial with motor vehicle accident survivors. Behaviour Research and Therapy, 50(10), 627-635.

The WHOQOL Group. (1995). The World Health Organization Quality of Life assessment (WHOQOL): position paper from the World Health Organization. Social Science \& Medicine, 41(10), 1403-1409.

Tivesten, E., Jonsson, S., Jakobsson, L., \& Norin, H. (2012). Nonresponse analysis and adjustment in a mail survey on car accidents. Accident Analysis \& Prevention, 48, 401-415.

van Delft-Schreurs, C. C. H. M., van Bergen, J. J. M., de Jongh, M. A. C., van de Sande, P., Verhofstad, M. H. J., \& de Vries, J. (2014). Quality of life in severely injured patients depends on psychosocial factors rather than on severity or type of injury. Injury, 45(1), 320-326.

Van der Velden, A. M., Kuyken, W., Wattar, U., Crane, C., Pallesen, K. J., Dahlgaard, J., Piet, J. (2015). A systematic review of mechanisms of change in mindfulness-based cognitive therapy in the treatment of recurrent major depressive disorder. Clinical Psychology Review, 37, 2639.

Varela, F. J., Thompson, E., \& Rosch, E. (1991). The embodied mind: cognitive science and human experience. Cambridge, Mass.: MIT préss.

Watzlawick, P., Bavelas, J. B., \& Jackson, D. D. (1967). Pragmatics of human communication: a study of interactional patterns, pathologies and paradoxes. New-York: WW Norton.

Watzlawick, P., Weakland, J. H., \& Fisch, R. (1974). Change: principles of problem formation and problem resolution. New-York: WW Norton

Wiseman, T., Foster, K., Curtis, K. (2016). The experience of emotional wellbeing for patients with physical injury: A qualitative follow-up study. Injury, International Journal of care Injured, 47, 1983-1989.

World Health Organization (2013). WHO guidelines on conditions specifically related to stress. ISBN: 978924150540 6, pp. 273.

\section{Appendix}

